\title{
Study on Growth Conditions for High Quality Hydrogenated Amorphous Silicon Oxide Films
}

\author{
Chao-Chao JIANG ${ }^{a}$, Jing JIN ${ }^{\mathrm{b}, *}$, Xing-Ling QU ${ }^{\mathrm{c}}$, Lu HUANG ${ }^{\mathrm{d}}$, Can LIU, Jia-Hua \\ MIN and Wei-Min SHI
}

College of Materials Science and Engineering, Shanghai University

No.333 Nanchen Road, Baoshan District, Shanghai

aj18801911474@163.com, bjjin@shu.edu.cn, 'c76973899@qq.com, ${ }^{\mathrm{d}}$ Ihuang@shu.edu.cn

*Corresponding author

Keywords: A-SiO $: \mathrm{H}$, Window layer, Fourier transform infrared spectroscopy, Optical band gap

\begin{abstract}
Wide band gap hydrogenated amorphous silicon oxide(a-SiO $\mathrm{x}: \mathrm{H})$ films were prepared by radio frequency plasma enhanced chemical vapor deposition(RF-PECVD) method. Nitrous oxide $\left(\mathrm{N}_{2} \mathrm{O}\right)$, hydrogen $\left(\mathrm{H}_{2}\right)$, silane $\left(\mathrm{SiH}_{4}\right)$ were used as source gases. With the increase of $\mathrm{N}_{2} \mathrm{O} / \mathrm{SiH}_{4}$ ratio from 0.5 to 2, the optical band gap of films changed in the range of $1.93 \sim 2.65 \mathrm{eV}$, and the hydrogen and oxygen contents were increased as well. The microstructure factor( $\left.\mathrm{R}^{*}\right)$ was used to characterize the degree of defect of films, and it was found that the increase of oxygen content could reduce the defect states. Moreover, we also studied the influence of RF power on the process of preparation. After comprehensive analysis, we got the best quality of films with optical band gap of $2.27 \mathrm{eV}$ and refractive index of 2.21 when $\mathrm{N}_{2} \mathrm{O} / \mathrm{SiH}_{4}$ ratio is 1 and $\mathrm{RF}$ power is $90 \mathrm{~W}$.
\end{abstract}

\section{Introduction}

Wide band gap materials are very important for improving the photovoltaic performance of Si-based thin-film solar cells. Hydrogenated amorphous silicon oxygen alloys with wide and adjustable band gap are widely used as window layers in thin-film solar cells[1].

There are many methods for the preparation of hydrogenated amorphous silicon oxide $(\mathrm{a}-\mathrm{SiO}: \mathrm{H})$ films, one of which is to use the RF-PECVD method[1,2]. Its advantage lies in that films are prepared in low temperature, which can promote photoelectric properties and reduce the defects of films. Usually, works by use of $\mathrm{CO}_{2}[3,4,5]$ as oxygen source gas have been reported, but rarely involved in $\mathrm{N}_{2} \mathrm{O}$ [6,7]. It is well known that various deposition parameters, like the flow rate of source gases, deposition pressure, RF power, and substrate temperature, etc, can affect the photoelectric and structural characteristics of films. In this paper, we paid more attention to the growth conditions of a-SiO ${ }_{x}: \mathrm{H}$ films prepared by PECVD method using $\mathrm{N}_{2} \mathrm{O}$ as oxygen source gas, and studied about influence of the $\mathrm{N}_{2} \mathrm{O} / \mathrm{SiH}_{4}$ ratio and $\mathrm{RF}$ power on the optical and structural properties of films.

\section{Experimental Details}

The a-SiO $\mathrm{x}: \mathrm{H}$ films were prepared on glass and Si substrates, respectively by RF-PECVD method, at $13.56 \mathrm{MHz}$ RF power with base pressure about $10^{-4} \mathrm{~Pa}$. Silane $\left(\operatorname{SiH}{ }_{4}\right)$, hydrogen $\left(\mathrm{H}_{2}\right)$ and nitrous oxide $\left(\mathrm{N}_{2} \mathrm{O}\right)$ were used as source gases. Samples deposited on glass substrates were used for optical characterization and that deposited on Si substrates were used for analysis of Fourier transform infrared(FTIR) spectroscopy and refractive index. Deposition conditions for different a-SiO $\mathrm{x}: \mathrm{H}$ films were summarized in Table 1 . The $\mathrm{N}_{2} \mathrm{O} / \mathrm{SiH}_{4}$ ratio was varied in the range of 0.5 -2, and silane and hydrogen gas flow rates were kept constant at 10 and $100 \mathrm{sccm}$ respectively. The substrate temperature and chamber pressure were also kept constant at $200^{\circ} \mathrm{C}$ and $90 \mathrm{~Pa}$, respectively. The RF power was varied from 30 to $120 \mathrm{~W}$. Optical band gap was measured by UV-Vis Spectrophotometer, and refractive index of films was measured by using spectroscopic ellipsometry. The scanning electron microscope (SEM) was used to observe the surface morphology of the film and the 
composition analysis was obtained by energy dispersive spectroscopy (EDS). The hydrogen and oxygen contents of films were calculated through the FTIR spectroscopy as well as the microstructure factor $\left(\mathrm{R}^{*}\right)$.

Table 1. Deposition conditions for different a-SiOx:H films

\begin{tabular}{lllllll}
\hline Parameter & \multicolumn{7}{c}{ a-SiO $\mathrm{x}: \mathrm{H}$} \\
\hline $\mathrm{N}_{2} \mathrm{O} / \mathrm{SiH}_{4}$ ratio & 1 & 1 & 1 & 1 & 0.5 & 2 \\
$\mathrm{RF}$ power[W] & 30 & 60 & 90 & 120 & 60 & 60 \\
Temperature[ $\left.{ }^{\circ} \mathrm{C}\right]$ & 200 & 200 & 200 & 200 & 200 & 200 \\
Pressure[Pa] & 90 & 90 & 90 & 90 & 90 & 90 \\
Optical band gap[eV] & 2.18 & 2.24 & 2.27 & 2.21 & 1.93 & 2.65 \\
Refractive index & 2.31 & 2.25 & 2.21 & 2.28 & 2.94 & 1.89 \\
Oxygen content & $6.7 \%$ & $14.6 \%$ & $18 \%$ & $11.1 \%$ & $8.7 \%$ & $17.1 \%$ \\
Hydrogen content & $7.3 \%$ & $11.2 \%$ & $15.2 \%$ & $21.7 \%$ & $6.3 \%$ & $10.7 \%$ \\
\hline
\end{tabular}

\section{Results and Discussion}

Optical band gap and refractive index of a- $\mathrm{SiO}_{\mathrm{x}}: \mathrm{H}$ films are given in Fig.1. Optical band gap $\left(\mathrm{E}_{\mathrm{g}}\right)$ is determined by Tauc's formula

$$
\left(\alpha h v^{1 / 2}\right)=(B)^{1 / 2}(h v-E g),
$$

where $h$ is Plank's constant, $v$ is optical frequency, $\alpha$ is absorption coefficient, and $B$ is a constant. $\left(\alpha h v^{1 / 2}\right)$ is plotted with $h v$ and a linear fit is drawn at the absorption edge region of optical frequency. The intercept of the linear plot is used as a measure of $\mathrm{E}_{\mathrm{g}}$. We observed an increase in optical band gap from 1.93 to $2.65 \mathrm{eV}$ as the $\mathrm{N}_{2} \mathrm{O} / \mathrm{SiH}_{4}$ ratio is increased from 0.5 to 2 . Refractive index of the films reduces from 2.94 to 1.89 by increasing the $\mathrm{N}_{2} \mathrm{O} / \mathrm{SiH}_{4}$ ratio. It is known that the window layer of the solar cell requires proper optical band gap and refractive index, which would match well with the i-type layer and achieve the optimum light transmission[8]. So, in order to obtain the effective distribution of the solar spectrum, we should choose appropriate refractive index, and form the DBR(distributed Bragg reflector) structure with other absorption layers to strengthen the selective light reflection[8].

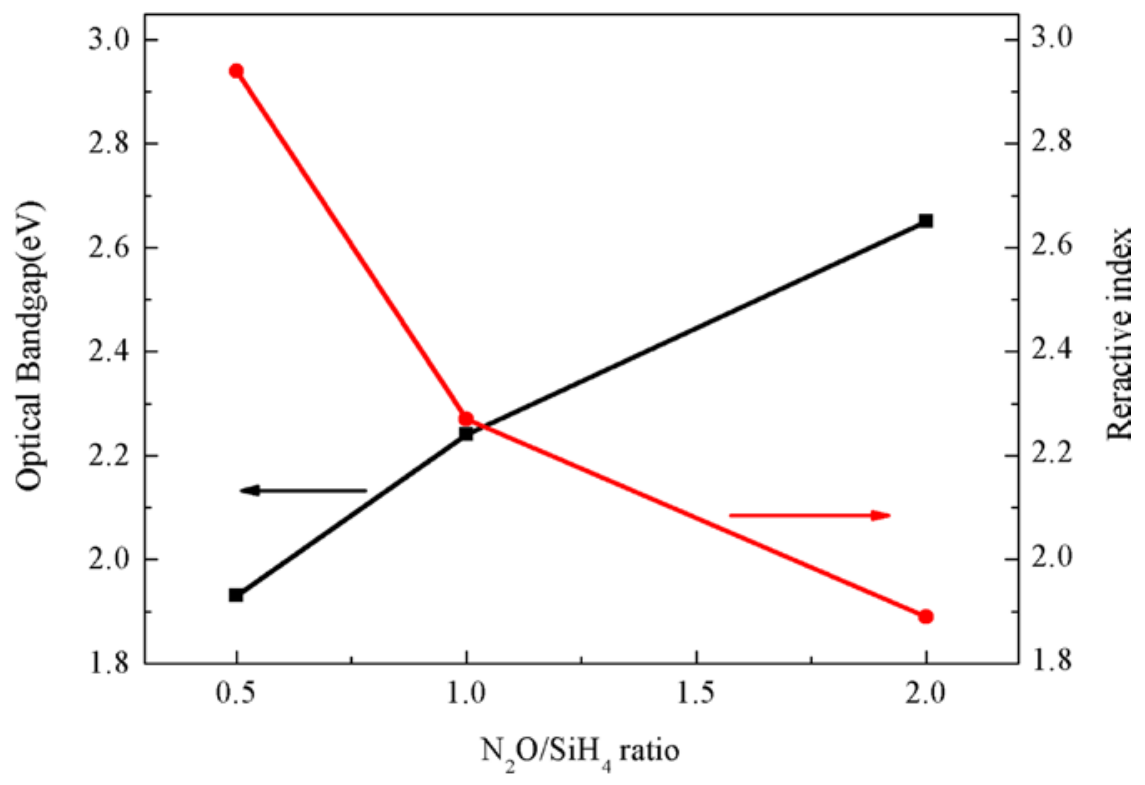

Fig.1 Optical band gap and refractive index with the different $\mathrm{N}_{2} \mathrm{O} / \mathrm{SiH}_{4}$ ratio.

With the help of Lucovsky's normalization constant [9], one can estimate oxygen and hydrogen 
content in these bonding configurations through evaluating integrated absorption of the respective FTIR absorption peaks. An integrated absorption in wavenumber interval of $940-1150 \mathrm{~cm}^{-1}$ has been used to estimate oxygen content of the film.

$$
C(O)=A^{\circ} I=0.156 \int_{940}^{1150} \alpha d E,
$$

where $C(O)$ is the oxygen content(units of at.\%), $A^{\circ}=0.156 \mathrm{at} \% / \mathrm{eV} \cdot \mathrm{cm}$, and $I=\int_{940}^{1150} \alpha d E$ is the integrated absorption in unit of $\mathrm{eV} \cdot \mathrm{cm}^{-1}$. Fig.2(a) shows FTIR absorption spectra within wavenumber interval of $940-1150 \mathrm{~cm}^{-1}$ for samples prepared with the $\mathrm{N}_{2} \mathrm{O} / \mathrm{SiH}_{4}$ ratio from 0.5 to 2 . We observed an increase in oxygen content from $8.7 \%$ to $17.1 \%$ as the $\mathrm{N}_{2} \mathrm{O} / \mathrm{SiH}_{4}$ ratio increases. The hydrogen content of films has been also evaluated from integrated absorption of the FTIR spectra with wavenumber interval of $1950-2300 \mathrm{~cm}^{-1}$ as shown in Fig.2(b) using

$$
C(H)=0.77 \int_{1950}^{2300} \alpha d E .
$$

The characteristic peaks at $2000 \mathrm{~cm}^{-1}$ and $2100 \mathrm{~cm}^{-1}$ are derived from the Si-H and Si- $\mathrm{H}_{2}$ bond stretching mode respectively, and the characteristic peaks at $2140 \mathrm{~cm}^{-1}, 2190 \mathrm{~cm}^{-1}$ and $2250 \mathrm{~cm}^{-1}$ are related to $\mathrm{H}_{2}-\mathrm{Si}(\mathrm{SiO}), \mathrm{H}-\mathrm{Si}\left(\mathrm{O}_{2} \mathrm{Si}\right)$ and $\mathrm{H}-\mathrm{Si}\left(\mathrm{O}_{3}\right)$ radical group respectively deriving from the $\mathrm{Si}-\mathrm{H}$ bond stretching mode. Stretching mode at $2100 \mathrm{~cm}^{-1}$ is generally considered more prone to the dangling bond or defect states[2]. We use the microstructure factor $\left(\mathrm{R}^{*}\right)$ to characterize the degree of defect of films[10,11].

$$
\mathrm{R}^{*}=\frac{\mathrm{I}_{2100}}{\mathrm{I}_{2000}+\mathrm{I}_{2100}+\mathrm{I}_{2140}+\mathrm{I}_{2190}+\mathrm{I}_{2250}} .
$$

When the $\mathrm{N}_{2} \mathrm{O} / \mathrm{SiH}_{4}$ ratio is 0.5 , the $\mathrm{R}^{*}$ has reached the maximum value. With further increasing the $\mathrm{N}_{2} \mathrm{O} / \mathrm{SiH}_{4}$ ratio, the peaks from FTIR absorption spectra move to the longer wavenumber. So, we know that the $\mathrm{R}^{*}$ reduces with increase of the $\mathrm{N}_{2} \mathrm{O} / \mathrm{SiH}_{4}$ ratio, when the ratio is more than 0.5. Considering the optical band gap and refractive index as mentioned above, the $\mathrm{N}_{2} \mathrm{O} / \mathrm{SiH}_{4}$ ratio of 1 is chosen to perform the following study about influence of the RF power on properties of films.
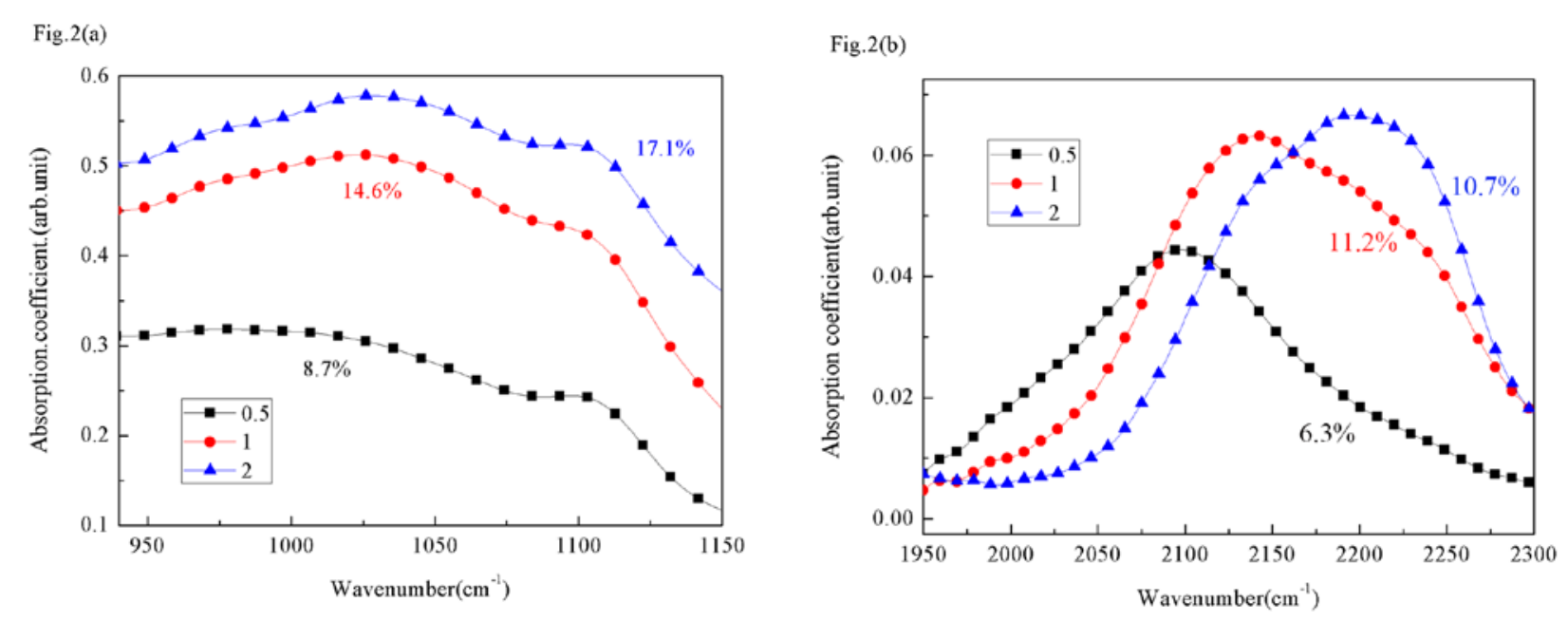

Fig. 2 The FTIR absorption spectra from (a) $940 \mathrm{~cm}^{-1}$ to $1150 \mathrm{~cm}^{-1}$ and (b) $1950 \mathrm{~cm}^{-1}$ to $2300 \mathrm{~cm}^{-1}$ wavenumber with the different $\mathrm{N}_{2} \mathrm{O} / \mathrm{SiH}_{4}$ ratio. The calculated oxygen and hydrogen contents are also shown respectively.

Optical band gap of $\mathrm{a}-\mathrm{SiO}_{\mathrm{x}}: \mathrm{H}$ films prepared in the different $\mathrm{RF}$ power is also determined by Tauc's formula, as seen in Fig.3(a). We observed that with increase of the power the curves shifted to the high energy, which meant that the optical band gap increases. When the RF power is $90 \mathrm{~W}$, the 
optical band gap reached the maximum value of $2.27 \mathrm{eV}$. However, continuously increasing the RF power to $120 \mathrm{~W}$, the optical band gap reduced to $2.21 \mathrm{eV}$. In addition, we used the infrared spectrum analysis to study the influence of the RF power on the structural characteristics of films. Fig.3(b) shows the relationship between the RF power and the oxygen content, and the change of the hydrogen content is shown in Fig.3(c). It is found that the oxygen content increases firstly and then decreases by increasing the RF power, which coincides with change in the optical band gap of films. However the hydrogen content increases remarkably as the RF power is much higher.

Fig.3(a)

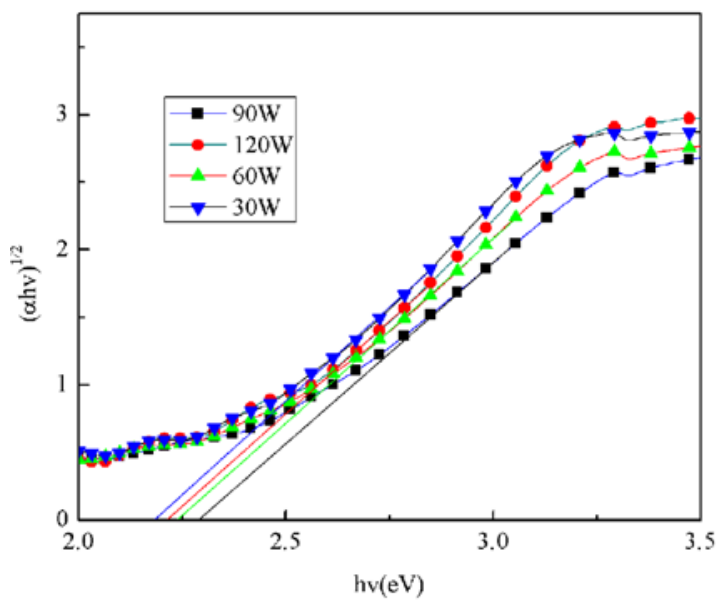

Fig.3(c)

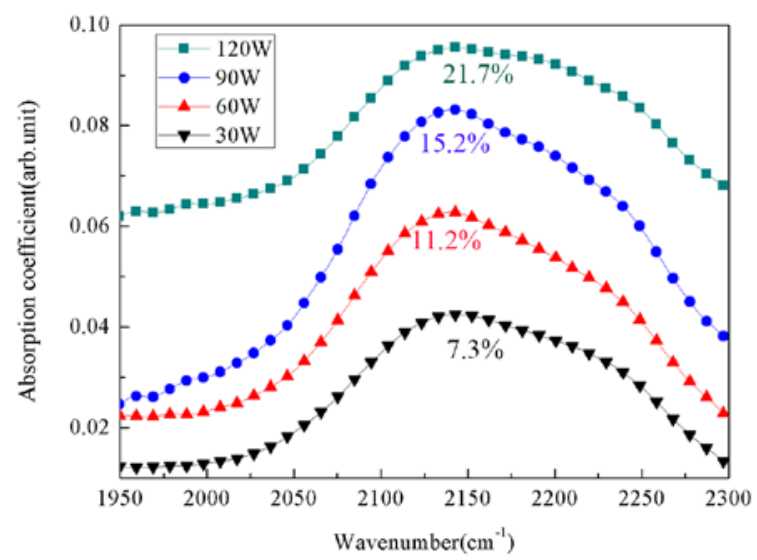

Fig.3(b)

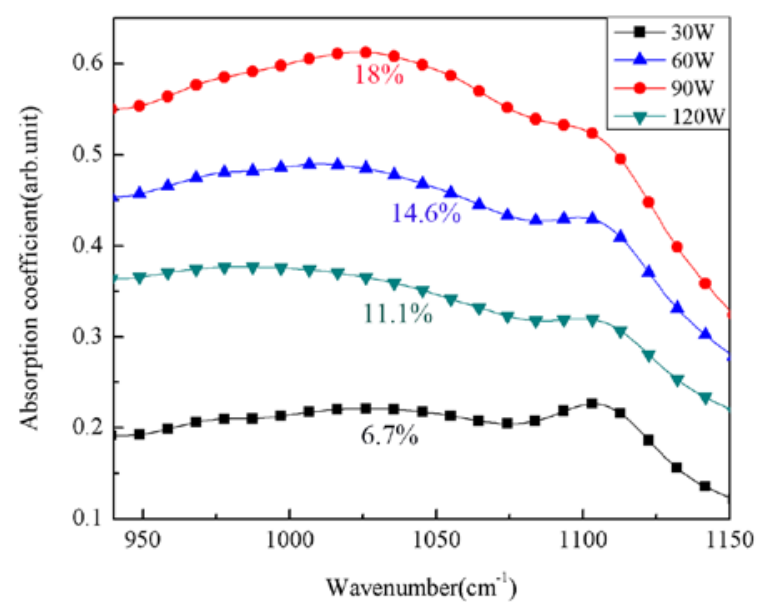

Fig.3(d)

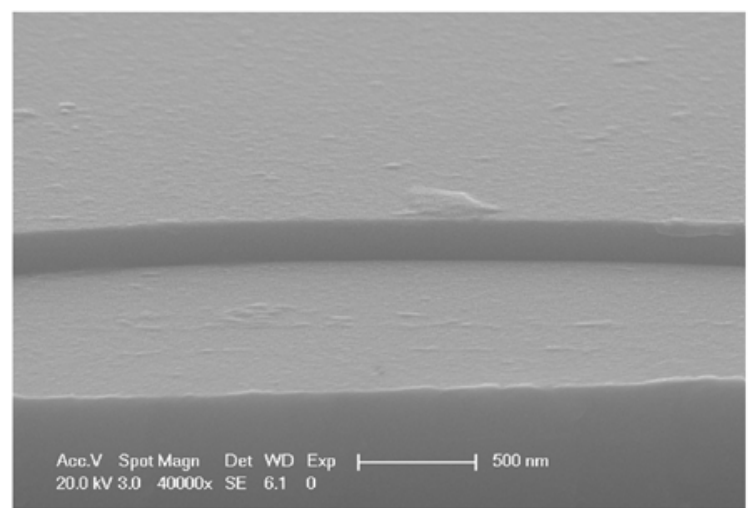

Fig.3(a) Optical band gap, the FTIR absorption spectra from (b) $940 \mathrm{~cm}^{-1}$ to $1150 \mathrm{~cm}^{-1}$ and (c) $1950 \mathrm{~cm}^{-1}$ to $2300 \mathrm{~cm}^{-1}$ wavenumber with the different RF power. Fig.3(d) shows the SEM image of a-SiO $: \mathrm{H}$ film with the $\mathrm{N}_{2} \mathrm{O} / \mathrm{SiH}_{4}$ ratio of 1 and the $\mathrm{RF}$ power of $90 \mathrm{~W}$. The calculated oxygen and hydrogen contents are also shown respectively.

From what has been discussed above, we may know that the increase of RF power leads to increase of electrons' temperature in the plasma, which promotes the decomposition of $\mathrm{N}_{2} \mathrm{O}$ and improves the oxygen content. The high power is more conducive to the decomposition of $\mathrm{SiH}_{4}$, thus greatly improving the hydrogen content and reduce the optical band gap. However, it may raise the concentration of $\mathrm{Si}-\mathrm{H}_{2}$ bond stretching mode, which leads to the increase of defects of films[2]. Therefore, the RF power of $90 \mathrm{~W}$ is acceptable in comparison. The surface morphology of films on the glass substrate was observed in Fig.3(d). From a whole point of view, the a-SiO $\mathrm{x}: \mathrm{H}$ films is amorphous and the surface is very smooth, which can satisfy the requirement for window layer in Si-based thin-film solar cells. 


\section{Conclusions}

1.The a-SiO ${ }_{x}: H$ films was prepared by using RF-PECVD method, and a phenomenon that the increase in $\mathrm{N}_{2} \mathrm{O} / \mathrm{SiH}_{4}$ ratio can significantly improve the optical band gap and oxygen content, and reduce the refractive index was been found.

2.Structural defect is observed to reduce at higher oxygen content, thus at wider optical band gap the film may have a radically reduced defect states. A reduction in the proportion of $\mathrm{Si}-\mathrm{H}_{2}$ bond stretching mode in films is expected to further improve the quality of the film.

3.By increasing the RF power, the optical band gap can be improved further. However, the optical band gap and oxygen content reduce, and hydrogen content of films increase obviously when the RF power is much higher.

4.Our best deposition condition was found that $\mathrm{N}_{2} \mathrm{O} / \mathrm{SiH}_{4}$ ratio is 1 and $\mathrm{RF}$ power is $90 \mathrm{~W}$. Under this deposition conditions, we got the film with optical band gap of $2.27 \mathrm{eV}$ and refractive index of 2.21 .

\section{Acknowledgement}

This work was supported by National Natural Science Foundation of China (Grant No. 61404080).

\section{References}

[1] Chonghoon Shin, S.M. Iftiqar, et al. Radio frequency plasma deposited boron doped high conductivity p-type nano crystalline silicon oxide thin film for solar cell window layer[J]. Materials Chemistry and Physics 159 (2015) 64-70.

[2] Shuo Wang, Yin Zhao, Dr.Friedhelm Finger. Study on wide bang gap amorphous silicon oxide materials and solar cells[D]. Tian Jin: Nankai University, 2014.

[3] Yasushi Sobajima, Shota Kinoshita, et al. Control of growth process for obtaining high-quality a-SiO ${ }_{x}: H[J]$. Can.J.Phys. 92:582-585 (2014).

[4] JaranSritharathikhun, SorapongInthisang, TaweewatKrajangsang. Optimization of an $\mathrm{i}-\mathrm{a}-\mathrm{SiO} \mathrm{x}: \mathrm{H}$ absorber layer for thin film silicon solar cell applications[J]. Thin Solid Films 546 (2013) 383-386.

[5] Kazuyoshi Nakada, ShinsukeMiyajima, Makoto Konagai. Amorphous silicon oxide passivation films for silicon heterojunction solar cells studied by hydrogen evolution[J]. Japanese Joumal of Applied Physics 53,04ER13 (2013).

[6] Jinjoo Park, Vinh Ai Dao, et al. A buffer-layer/a-SiO $\mathrm{x}: \mathrm{H}(\mathrm{p})$ window-layer optimization for thin film amorphous silicon based solar cells[J]. Thin Solid Films 546 (2013) 331-336.

[7] Yu-Hung Chen, Yung-Tsung Liu, et al. Improved photovoltaic properties of amorphous silicon thin-film solar cells with an un-doped silicon oxide layer[J]. Materials Science in Semiconductor Processing 31 (2015) 184-188.

[8] Dan-Li Zhao, Yin Zhao. Si based thin-film solar cells (8). Nankai University. Solar Energy 17 (2012)

[9] G. Lucovsky, J. Yang, S.S. Chao, J.E. Tyler, W. Czubatyj, Phys. Rev. B 28 (1983) 3225-3233.

[10] Xu Y, Liao X, Kong G, et al. Microstructure characterization of transition films from amorphous to nano crystalline silicon[J]. Journal of Crystal Growth, 2003, 256(1-2):27-32.

[11] Mahan A H, Raboisson P, Williamson D L, et al. Evidence for microstructure in glow discharge hydrogenated amorphous Si-C alloys[J]. Solar Cells, 1987, 21(1-4):117-126.

[12] Kichan Yoon, Youngkuk Kim, JinJoo Park, Chong Hoon Shin. Journal of Non-Crystalline Solids 357 (2011) 2826-2832 